\title{
Diseases Associated with Stigma: A Review
}

\author{
Peter Ekpunobi Chime ${ }^{*}$, Paul Chibuike Okoli1, Ethel Nkechi Chime², Chijioke Chinedu Anekpo ${ }^{3}$, \\ Augustine Obumneme Ozougwu1 ${ }^{1}$, Philip Chukwuma Ofojebe ${ }^{4}$
}

\author{
${ }^{1}$ Department of Internal Medicine, ESUT College of Medicine, Enugu State University of Science and Technology, Enugu, Nigeria \\ ${ }^{2}$ Department of Otorhinolaryngology, University of Nigeria, Ituku-Ozala Campus, Enugu, Nigeria \\ ${ }^{3}$ Department of Otorhinolaryngology, Enugu State University of Science and Technology, Enugu, Nigeria \\ ${ }^{4}$ Department of Psychology, Nnamdi Azikiwe University, Awka, Nigeria \\ Email: pe4chyme@yahoo.com, okolipd71@gmail.com, ethel.chime@unn.edu.ng, \\ chijioke.anekpo@esut.edu.ng, austin.ozo.flex@gmail.com,frcpofojebe@gmail.com
}

How to cite this paper: Chime, P.E., Okoli, P.C., Chime, E.N., Anekpo, C.C., Ozougwu, A.O. and Ofojebe, P.C. (2022) Diseases Associated with Stigma: A Review. Open Journal of Psychiatry, 12, 129-140.

https://doi.org/10.4236/ojpsych.2022.122011

Received: January 19, 2022

Accepted: February 28, 2022

Published: March 3, 2022

Copyright (c) 2022 by author(s) and Scientific Research Publishing Inc. This work is licensed under the Creative Commons Attribution International License (CC BY 4.0).

http://creativecommons.org/licenses/by/4.0/

(c) (i) Open Access

\begin{abstract}
Background: When a disease is associated with stigma, there may be attendant negative consequences. Purpose: This review was to show how stigmaassociated diseases impact negatively on the psychological and social wellbeing of the affected persons. Methods: The relevant articles for the review were obtained through PubMed and Google Scholar search on the internet using relevant keywords. Results: Several infectious and non-infectious diseases are associated with stigma. The causes of stigma in these diseases include fear of contracting the disease and dying from it, disfiguring caused by the disease and ignorance and misconception concerning the cause, nature and infectivity of the disease. Those suffering from stigma-associated diseases are usually discriminated against and denied the privileges and opportunities available for those not suffering from stigma-associated diseases. This often leads to psychosocial or psychiatric complications such as social isolation, depression or even suicidal ideation. Conclusions: Stigma-associated diseases still remain a very important health problem with attendant psychosocial consequences. Multi-disciplinary and multi-level efforts are required for its effective mitigation.
\end{abstract}

\section{Keywords}

Stigma, Hearing Loss and Cleft Palate, Leprosy, Mental Ill-Health and Suicide, Lassa Fever and HIV/AIDS

\section{Introduction}

Stigma is defined in the Merriam-Webster dictionary as "a mark of shame or discredit" and also as "a set of negative and often unfair beliefs that a society or 
group of people have about something" [1]. The stigmatized person has an attribute or a characteristic which the society considers undesirable. Thus he is despised or discriminated against. There are cases where there may be clear grounds for this as in the case of Ebola or Lassa fever which is infectious and very deadly, or in the case of leprosy because of its high morbidity. However, stigma is based on misconceptions and misunderstandings of the condition that is associated with the stigma in some cases. A wide range of conditions are associated with stigma and they include some diseases and behaviours or practices that are considered abnormal as adjudged by the culture of the people, i.e., conditions that do not conform to the norms of the society. Some of the conditions associated with stigma are listed in Table 1. Among stigma-associated diseases, some are infectious diseases and some are non-infectious diseases (Table 2).

It is important to recognize stigma-associated diseases because such diseases in addition to physical morbidity, can also be associated with psychosocial morbidity. The affected individual may not have the courage to declare his illness because of the adverse consequences that may follow which may include losing his job [2]. He may suffer in silence or resort to quackery and either of these will likely increase the physical and psychological morbidities of the disease. If it is an infectious disease, it may spread to others because of the delay in treatment. Also, the stigmatized individual may be denied the privileges and opportunities

Table 1. Some disease and non-disease conditions that are associated with stigma.

\begin{tabular}{|c|c|}
\hline Diseases & Non-disease conditions \\
\hline Leprosy & Abject poverty \\
\hline Hearing loss & The lowest in a caste system \\
\hline Speech impairment & Some beliefs \\
\hline Cleft palate/cleft lip & Rastafarianism \\
\hline Ebola & $\begin{array}{l}\text { Deviant practices, e.g., lesbianism, homosexuality or } \\
\text { transgenderism }\end{array}$ \\
\hline Lassa Fever & $\begin{array}{l}\text { State of not being married (being a spinster or } \\
\text { bachelor) in some culture }\end{array}$ \\
\hline \multicolumn{2}{|l|}{ Sexually transmitted diseases } \\
\hline \multicolumn{2}{|l|}{ Obesity } \\
\hline \multicolumn{2}{|l|}{ Epilepsy } \\
\hline \multicolumn{2}{|l|}{ Mental ill-health } \\
\hline \multicolumn{2}{|l|}{ Drug abuse/drug dependence } \\
\hline \multicolumn{2}{|l|}{ Suicidal ideation/Suicide } \\
\hline \multicolumn{2}{|l|}{ Infertility } \\
\hline $\begin{array}{l}\text { Physical disability arising from } \\
\text { poliomyelitis }\end{array}$ & \\
\hline
\end{tabular}


Table 2. Some infectious and non-infectious diseases that are associated with stigma

\begin{tabular}{ll}
\hline \multicolumn{1}{c}{ Infectious diseases } & \multicolumn{1}{c}{ Non-infectious diseases } \\
\hline Leprosy & Infertility \\
Ebola & Epilepsy \\
Lassa Fever & Hearing loss \\
Sexually transmitted diseases e.g., & Speech impairment \\
HIV/AIDS & Obesity \\
& Cleft palate/cleft lip \\
& Drug abuse/drug dependence \\
& Mental ill-health \\
& Suicidal ideation/Suicide \\
& Physical disability arising from poliomyelitis \\
\hline
\end{tabular}

that are available for non-stigmatized individuals [3] [4]. Such opportunities may include marriage, employment, renting an apartment or belonging to an association. All these can lead to psychosocial or psychiatric complications such as reduced self-worth, social isolation or depression.

In this review, we are only concerned with disease conditions that are associated with stigma. The objective of this article is to do a review of some of the stigma-associated diseases in order to show how stigma can impact negatively on the psychological and social wellbeing of the afflicted.

\section{Methodology}

This review was based on electronically searched articles on stigma-associated diseases written in English. PubMed and Google Scholar databases were searched using the following search terms: "stigma", "leprosy", "cleft palate", "cleft lip", "Ebola", "Lassa fever", "sexually transmitted diseases", "hearing loss", "mental illness", "suicide". The search for related articles was not time restricted. The references of the selected articles were also searched for additional useful information. The websites of the World Health Organization (WHO) and Centers for Disease Control and Prevention (CDC) were also consulted. The synthesis was narrative.

\section{Result (Findings) Diseases Associated with Stigma}

\subsection{Leprosy}

Leprosy has been with man for a very long time. Issues relating to leprosy or lepers were mentioned in the Holy Bible both in the Old Testament [5] and the New Testament [6] [7] [8]. It should be noted that in the Holy Bible, the term leprosy was used for different types of skin conditions including Hansen's disease [5]. It was not until 1873 that Mycobacterium leprae, the cause of leprosy 
[or Hansen's disease] was isolated [9] and the disease was properly defined. Mycobacterium leprae, an acid-fast bacillus, can be isolated from leprosy lesion. Segregation and stigma associated with leprosy were also mentioned in the Holy Bible, although the reasons were to prevent others from being infected.

Following infection, Mycobacterium leprae grows very slowly in human body causing damage to the body tissues [10] [11]. One of the complications of leprosy is loss of sensation which includes pain sensation. The consequence of this is that there is damage to some parts of the body, especially the hands and feet, due to repeated injury and scarring. The external manifestations of leprosy and the fear of contracting the disease are among what fuels stigma in leprosy [12].

Leprosy is a treatable disease [10]. However, the treatment for the disease sometimes results in adverse immunological reaction which can further damage the skin of the sufferer. In the past, lepers were segregated and made to live in colonies where they were treated [9].

The World Health Organization (WHO) recommends multidrug therapy for leprosy for effective treatment [10]. Early treatment will prevent or limit complications [10]. It will also prevent the spread of the disease to others. However, the problem is that the patient may not feel encouraged to declare his illness for fear of losing his job [2] or his place of residence, or he may not even be aware that the disease is treatable. The consequence of all these is that there is a delay in initiating treatment resulting in increased chances of body's disfiguring by the disease and thus increased chances of stigma.

Even after the leprosy has been successfully treated, the stigma still persists because of the residual deformity to the hands, feet, body and eyes. Psychotherapeutic intervention is necessary to help the afflicted cope with his condition. Occupational rehabilitation is also important to enable him to earn a living. Such will keep him occupied most of the time and will make him think less of his ailment.

\subsection{Hearing Loss and Speech Impairment}

Hearing loss can occur at any age. However, hearing loss is very common among the elderly where the prevalence can be $50 \%$ or higher [13]. A person with severe hearing loss will have difficulty interacting with people [14]. The problem will even be worse if the person is also dumb. Hearing and/or speech impaired person may feel isolated and depressed. In a place where special school for the deaf and dumb is not available, he will not have the opportunity to attend formal education and this will further limit his opportunities in future. In children, hearing loss significantly impairs language development [15].

Hearing loss can be caused by physical or acoustic trauma, developmental anomaly or ear infections. Wax impaction is a common and treatable cause of hearing loss [16]. A person presenting with hearing loss should be thoroughly examined and investigated. Hearing thresholds assessment will help to determine the type of hearing loss, whether it is sensorineural, conductive or mixed 
hearing loss. Also, hearing thresholds assessment will help to determine the severity of the hearing loss. All these will help to determine those that will need hearing aid. Options in managing hearing loss include cochlear transplant [17] and hearing aid [18].

Any form of intervention that will improve the hearing function of the affected person will improve his inter-personal interaction and will mitigate stigmatization. However, some of the challenges faced in the rehabilitation of people living with hearing loss are that hearing aids are expensive and cochlear transplant surgery is also expensive and the patient may not be able to afford the cost of treatment.

\subsection{Cleft Palate/Cleft Lip}

Cleft palate and cleft lip are developmental anomalies that result from incomplete closure of the facial structures. Cleft lip/palate can occur in isolation. Cleft palate has also been found to occur in association with hearing loss is some disease conditions such as Stickler syndrome (hereditary progressive arthro-ophthalmopathy), Treacher Collins Syndrome, Smith-Lemli-Opitz syndrome and Genitopatellar syndrome.

The primary function of the palate is to demarcate the oral cavity from the nasal cavity. In cleft palate, the demarcation is breached resulting in nasal regurgitation and feeding difficulty [19]. Also sleep-disordered breathing including obstructive sleep apnea can occur in patients with cleft palate [20].

Speech disorders are common in cleft palate [21]. The affected person may have poor speech as well as nasal speech. The disfigured face caused by the cleft palate and cleft lip as well as the poor speech contributes to the stigma found among these individuals. The stigma in orofacial cleft affects not only the afflicted but also the family of the afflicted person [22]. A study showed that many parents were ignorant as to the exact cause of orofacial cleft and seventy-three percent of the mothers were ashamed to have children with cleft palate and cleft lip [22]. The family of the afflicted child felt stigmatized by their neighbours some of who refused to touch the child [22].

Cleft palate is amenable to surgery, but the surgery is expensive and the patient may not be able to afford it.

\subsection{Ebola Virus Disease (EVD) and Lassa Fever}

Ebola virus disease and Lassa fever belong to the group of diseases that is referred to as viral haemorrhagic fevers [23]. Viral haemorrhagic fevers are caused by viruses. Ebola virus diseaseor Ebola haemorrhagic fever is caused by Ebola virus while Lassa fever is caused by Lassa virus [23].

Infection by Ebola virus or Lassa virusinitially leads to non-specific febrile illness although it may be asymptomatic in some cases [23] [24] [25]. The infection may progress to severe illness with multiple organ failure and death. For Lassa fever, Ribavirin is the antiviral agent of choice while for Ebola virus dis- 
ease; there is no specific antiviral agent [23]. Supportive care is very important in all symptomatic cases of viral haemorrhagic fevers. Coagulopathy and bleeding are remarkable features of viral haemorrhagic fevers.

Treatment and nursing of viral haemorrhagic fever patients involve the use of personal protective equipment (PPE) [23]. Viral haemorrhagic fevers are deadly and very infectious. Because of this, there are special and standard protocols for handling the bodies of people who died from the disease. The dead body is usually put in double body bags and buried by government officials.

The high infectivity and high mortality rate of viral haemorrhagic fevers make them to be dreaded and stigma-associated. Even health care workers and caregivers are scared of contracting viral haemorrhagic fever and dying from it. This is coupled with the fact that the body of the dead patient is not released to the relatives for burial. This is a very important issue among some tribes such as the Igbos of Nigeria which has the culture of according a special and decent burial to their dead relatives.

Stigma in viral haemorrhagic fever can persist even after the patient has recovered from the acute illness [26].

\subsection{Sexually Transmitted Diseases (STDs)}

There are different types of sexually transmitted diseases and they include gonorrhea, syphilis, genital herpes, trichomoniasis, granulomainguinale (Donovanosis), lymphogranuloma venereum, and human immunodeficiency virus infection [27]. Even before the emergence of human immunodeficiency virus infection and acquired immunodeficiency syndrome (HIV/AIDS), sexually transmitted diseases (STDs) are associated with stigma because STDs are associated with promiscuity and immoral behavior. In HIV/AIDS, the stigma associated with sexually transmitted diseases is even more pronounced. In addition to the social stigma, persons living with HIV/AIDS also feel stigmatized by the healthcare professionals because of the extra measures these professionals may take when taking care of them in the hospital [28].

A person with HIV/AIDS will develop a feeling of guilt and regret and may not have the courage to declare his illness and visit the hospital for treatment early enough. The affected person may even be in a state of denial initially making him not go for treatment on time. When people around him find out the nature of his illness, they may deride him and subject him to social discrimination. Due to stigma and depression, suicidal thoughts were found to be common among people living with HIV/AIDS in Nigeria [29].

Some of the sexually transmitted diseases are treatable [27]. Although, there is currently no cure for HIV/AIDS, treatment can significantly reduce the morbidity associated with the disease and also prolong the life of the affected person.

In HIV/AIDS, the associated stigma can be mitigated by getting the society to be more tolerant with persons living with HIV/AIDS and also by helping the affected persons to cope with the disease [30]. 


\subsection{Epilepsy}

Just like leprosy, epilepsy is another stigma-associated disease that was mentioned in the Holy Bible [31] [32] [33]. Epilepsy is a chronic neurological disorder which in its classical form manifests with seizures. When the affected person has generalized seizures with loss of consciousness, it may look terrifying to the onlookers [31] [33].

Epilepsy can be caused by a wide range of things such as trauma to the head, stroke, developmental anomaly, infections and tumor. In some cases, no cause can be found. Special laboratory investigations for epilepsy include electroencephalography to determine the nature of the abnormal electrical activities of the brain and brain imaging, preferably, magnetic resonance imaging (MRI) to see if there is any structural abnormality such as brain tumour or cerebral infarction.

The seizures can be controlled with anticonvulsants and several anticonvulsants are available to choose from. [34]. Where a cause exists as in the case of brain tumour, the cause should be treated. Some cases of epilepsy will require treatment for life.

Epilepsy is associated with stigma [35]. In Nigeria, the burden of stigma associated with epilepsy has been found to be very high [36]. The affected person is more likely to feel stigmatized if his epileptic attack occurs in public, i.e., if an outsider gets to know that he is living with epilepsy [36]. The stigma associated with epilepsy arose from misconception and misunderstanding of the disease [4]. In the bible, epilepsy was thought to be caused by evil spirit [3] [32] [33]. The stigma in a person that is living with epilepsy gives him a feeling of shame, rejection and loneliness [35]. In Nigeria for example among Igbos, nobody will like to marry a person living with epilepsy.

\subsection{Mental Ill-Health or Poor Mental Health}

People with mental ill-health or poor mental health are those with mental or behavioural disorders. They include those with bipolar disorder, mania, depression, dementia, schizophrenia, anxiety disorder, post-traumatic stress disorder (PTSD), substance abuse and suicidal behaviour disorder [37] as well as those with retarded mental development and degenerative central nervous system disease. People with mental ill-health or poor mental health are among the most stigmatized.

Because of the wide and varied nature of mental health problems and their aetiological factors, a wide range of therapists are involved in the management of the medical, psychological and social challenges posed by these clinical problems. They include physicians, psychiatrists, clinical psychologists, medical social workers, occupational therapists, sociologists, clergies and even herbalists.

A psychotic individual is presumed to be dangerous and unpredictable [38]. This is part of what fuels prejudice, antagonism and social segregation against such mentally ill individuals. In the Middle Ages, the mentally ill were imprisoned, burnt or killed [38]. At the present time, some cultures still encourage the 
chaining and flogging of the mentally ill especially if he is considered to be violent, a condition which ordinarily would require a major tranquilizer. Because most psychotic illnesses run a chronic cause, the associated stigma is a life-long challenge.

\subsection{Suicidal Ideation and Suicide}

Suicide is defined in the Merriam-Webster dictionary as "the act or an instance of taking one's own life voluntarily and intentionally" [39]. Attempted suicide is when someone attempted and failed to end his/her life. Suicidal ideations, "often called suicidal thoughts or ideas, is a broad term used to describe a range of contemplations, wishes, and preoccupations with death and suicide" [40].

Globally the suicide rate is high, about 700,000 per year [41]. Traditional suicide method used to be by hanging, but now self-poisoning and shooting oneself are other common methods of committing suicide. The new trend which is very worrisome is that when some people want to commit suicide, they will kill their wives and children before killing themselves. This trend is currently observed in the United States of America. "Many suicides happen impulsively in moments of crisis with a breakdown in the ability to deal with life stresses, such as financial problems, relationship break-up or chronic pain and illness" [41].

Suicide impacts negatively on the affected person, his family, his community and his country. In some African culture, suicide is considered to be a very strong taboo. In Igbo culture, when somebody hangs himself in a forest, his family will pay an herbalist to bring down the body and have it buried in the forest. Afterwards the family will say that the person is missing rather than admit that he has committed suicide. This is an attempt to get the stigma of suicide off the family. This is an example of stigma operating at the family level. The challenges that are posed by suicide require a multidisciplinary approach involving physicians, psychiatrists, clinical psychologists, medical social workers, sociologists and clergies.

Suicide is a big problem among patients with depression. Both mental illness and suicide are associated with stigma.

\section{Discussion}

Diseases that are associated with stigma are many and consist of infectious and non-infectious diseases. Some are treatable while some run a chronic and disabling course. This review was not exhaustive with the list of stigma-associated diseases. In addition to the stigma-associated diseases listed in Table 2, others are blindness, stuttering, albinism, tuberculosis, hepatitis, small pox, chicken pox, hepatitis, skin diseases, and skeletal abnormalities such as kyphosis, scoliosis, genuvarum and genu valgum. As it will be very difficult to discuss all these diseases in one paper, only limited examples were used to show how stigma can impact negatively on the affected individuals.

The cause of stigma in some of the diseases is because the diseases are deadly 
and people are afraid of contracting such diseases. Examples of diseases with high mortality rates are Lassa fever [42] and Ebola. For diseases like leprosy and cleft palate, the disfiguring associated with them is partly responsible for the stigma. However, ignorance and misconception also play some roles in stigma. People who suffered from leprosy, Lassa fever and Ebola are still discriminated against even after they have been successfully treated and rendered non-infectious. Epilepsy was thought to be caused by evil spirit [3] [32] [33] while some people think that epilepsy is infectious.

Despite the long history of stigma, people's attitude to stigma-associated diseases has not changed much. Even at the present time, individuals with stigma-associated diseases are sometimes treated harshly, cruelly and crudely. Psychotic patients are sometimes chained and flogged instead of being taken to the hospital. This happens in herbalist's homes and even in some churches. As recently as in 2021, some drug addicts were flogged mercilessly and openly in village squares in some parts of Nigeria (The authors do not have the permission to upload the videos). Although this method of treatment may appear very crude and terrifying, the interventionists found it to be very effective in curtailing drug dependence and drug addiction. This is an example of stigma operating at the community level. The villagers felt that the actions of those drug addicts were bringing shame to their community. The treatment they meted out to the drug addicts was an attempt to get rid of the stigma caused by the drug addicts in their community. Sometimes people with stigma-associated diseases are denied some privileges available to non-stigmatized individuals [2] [3] [4].

There are several obstacles to mitigating or eradicating stigma. The fear of stigma or ignorance concerning availability of treatment may make the affected individual hide his ailment rather than come out for treatment. Cost can also be a problem. For example, a deaf individual who requires a hearing aid or cochlear transplant may not afford the high cost. For such people, hearing aid will significantly improve their hearing which will improve their quality of life. Surgical repair of cleft palate is also very expensive and this is a major challenge in developing countries where most people pay for their healthcare themselves.

In Nigeria, proliferation of new generation churches and pastors who claim to be able to cure every disease through miracles and prayers is a major challenge. These new generation churches and pastors confuse and distract the affected individuals from seeking proper intervention for their diseases and other problems. The affected individuals also waste the money that they would have used in treating themselves.

Tackling the challenges posed by stigma is a herculean task that requires a multidisciplinary approach at the patient's, family and society level (multi-level approach). Efforts should be made to correct the misconceptions about diseases at the society level. For example, it can be taught in schools and churches that epilepsy is not infectious and also that epilepsy is not caused by evil spirits.

One method used in the past to reduce stigmatization associated with leprosy 
was to change the name of leprosy to Hanson's disease [43]. Another name suggested for leprosy was mycobacterial neurodermatosis [43]. Such innovative ideas can be tried in other stigma-associated diseases. In the case of HIV/AIDS, attempts were made to mitigate the associated stigma by getting the society to be more tolerant with persons living with HIV/AIDS and also by helping the affected persons to cope with the disease [30].

\section{Conclusion}

Stigma associated with several infectious and non-infectious diseases has persisted because of ignorance and misconception surrounding those diseases. Thus, the adverse psychological and social consequences on the individuals suffering from those diseases have continued. Mitigation or eradication of the stigma associated with diseases as well as the psychosocial effects of the stigma will require a multi-disciplinary and multi-level approach.

\section{Conflicts of Interest}

The authors declare no conflicts of interest with regards to this study.

\section{References}

[1] Merriam-Webster Dictionary (n.d.) Stigma. https://www.merriam-webster.com/dictionary/stigma

[2] American Psychiatric Association (2020) Stigma, Prejudice and Discrimination against People with Mental Illness.

https://www.psychiatry.org/patients-families/stigma-and-discrimination

[3] Phdessay (2018, December 17) Stigma, Discrimination and the Concept of Social Exclusion.

https://phdessay.com/stigma-discrimination-and-the-concept-of-social-exclusion/

[4] Kaculini, C.M., Tate-Looney, A.J. and Seifi, A. (2021) The History of Epilepsy: From Ancient Mystery to Modern Misconception. Cureus, 13, Article ID: e13953. https://doi.org/10.7759/cureus.13953 https://www.ncbi.nlm.nih.gov/pmc/articles/PMC8051941/

[5] (2022)2022 King James Bible Online. Num 5: 2. https://www.kingjamesbibleonline.org/index.php

[6] (2022) 2022 King James Bible Online. Matthew 12: 13. https://www.kingjamesbibleonline.org/index.php

[7] (2022) 2022 King James Bible Online. Mark 3: 5. https://www.kingjamesbibleonline.org/index.php

[8] (2022) 2022 King James Bible Online. Luke 6: 10. https://www.kingjamesbibleonline.org/index.php

[9] Azizi, M.H. and Bahadori, M. (2011) A History of Leprosy in Iran during the 19th and 20th Centuries. Archives of Iranian Medicine, 14, 425-430.

[10] World Health Organization (2021, May 10) Facts Sheet: Leprosy (Hansen's Disease). https://www.who.int/news-room/fact-sheets/detail/leprosy

[11] Centers for Disease Control and Prevention (n.d.) Hansen's Disease (Leprosy). https://www.cdc.gov/leprosy/symptoms/index.html 
[12] Sermrittirong, S. and Van Brakel, W.H. (2014) Stigma in Leprosy: Concepts, Causes and Determinants. Leprosy Review, 85, 36-47. https://doi.org/10.47276/lr.85.1.36

[13] Cunningham, L.L. and Tucci, D.L. (2017) Hearing Loss in Adults. The New England Journal of Medicine, 377, 2465-2473. https://doi.org/10.1056/NEJMra1616601

[14] Wallhagen, M.I. (2010) The Stigma of Hearing Loss. The Gerontologist, 50, 66-75. https://doi.org/10.1093/geront/gnp107

[15] Shojaei, E., Jafari, Z. and Gholami, M. (2016) Effect of Early Intervention on Language Development in Hearing-Impaired Children. Iranian Journal of Otorhinolaryngology, 28, 13-21.

[16] Adobamen, P.R. andOgisi, F.O. (2012) Hearing Loss Due to Wax Impaction. Nigerian Quarterly Journal of Hospital Medicine, 22, 117-120.

[17] US Food and Drug Administration (2021) Benefits and Risks of Cochlear Implants. https://www.fda.gov/medical-devices/cochlear-implants/benefits-and-risks-cochlear -implants

[18] Okokhere, P.O., Ibekwe, T.S. and Akpede, G.O. (2009) Sensorineural Hearing Loss in Lassa Fever: Two Case Reports. Journal of Medical Case Reports, 3, Article No. 36. https://doi.org/10.1186/1752-1947-3-36

[19] Goswami, M., Jangra, B. and Bhushan U. (2016) Management of Feeding Problem in a Patient with Cleft Lip/Palate. International Journal of Clinical Pediatric Dentistry, 9, 143-145. https://doi.org/10.5005/jp-journals-10005-1351

[20] Robison, J.G. and Otteson, T.D. (2011) Increased Prevalence of Obstructive Sleep Apnea in Patients with Cleft Palate. Archives of Otolaryngology. Head and Neck Surgery, 137, 269-274. https://doi.org/10.1001/archoto.2011.8

[21] Kummer, A.W. (2014) Speech Evaluation for Patients with Cleft Palate. Clinics in Plastic Surgery, 41, 241-251. https://doi.org/10.1016/j.cps.2013.12.004

[22] Adeyemo, W.L., James, O. and Butali, A. (2016) Cleft Lip and Palate: Parental Experiences of Stigma, Discrimination, and Social/Structural Inequalities. Annals of Maxillofacial Surgery, 6, 195-203. https://doi.org/10.4103/2231-0746.200336

[23] Fhogartaigh, C.N. and Aarons, E. (2015) Viralhaemorrhagic Fever. Clinical Medicine, 15, 61-66. https://doi.org/10.7861/clinmedicine.15-1-61

[24] Baron, R.C., McCormick, J.B. and Zubeir, O.A. (1983) Ebola Virus Disease in Southern Sudan: Hospital Dissemination and Intrafamilial Spread. Bulletin of the World Health Organization, 61, 997-1003.

[25] World Health Organization (2022) Lassa Fever. http://www.who.int/mediacentre/factsheets/fs179/en/

[26] Idigbe, I.E., Salu, O.B., Amoo, O.S., Musa, A.Z., Shaibu, J.O., et al. (2020) Dealing with Stigma and Its Impact on Lassa-Fever Survivors in Ondo State. Trends in Research, 3, 1-2. https://oatext.com/pdf/TR-3-158.pdf

[27] Centers for Disease Control and Prevention (2006) Sexually Transmitted Diseases Treatment Guidelines, 2006. Morbidity and Mortality Weekly Report, 55, 42-49.

[28] Arias-Colmenero, T., Pérez-Morente, M.Á., Ramos-Morcillo, A.J., Capilla-Díaz, C., Ruzafa-Martínez, M. and Hueso-Montoro, C. (2020) Experiences and Attitudes of People with HIV/AIDS: A Systematic Review of Qualitative Studies. International Journal of Environmental Research and Public Health, 17, Article No. 639. https://www.ncbi.nlm.nih.gov/pmc/articles/PMC7014086/

[29] Shittu, R., Alabi, M., Odeigah, L., Sanni, M., Issa, B., et al. (2014) Suicidal Ideation among Depressed People Living with HIV/AIDS in Nigeria, West Africa. Open Jour- 
nal of Medical Psychology, 3, 262-270. https://doi.org/10.4236/ojmp.2014.33027

[30] Brown, L., Macintyre, K. and Trujillo, L. (2005) Interventions to Reduce HIV/AIDS Stigma: What Have We Learned? AIDS Education and Prevention, 15, 49-69. https://doi.org/10.1521/aeap.15.1.49.23844

[31] (2022) 2022 King James Bible Online. Matthew 17: 14-20. https://www.kingjamesbibleonline.org/index.php

[32] (2022) 2022 King James Bible Online. Mark 9: 17-22. https://www.kingjamesbibleonline.org/index.php

[33] (2022) 2022 King James Bible Online. Luke 9: 42. https://www.kingjamesbibleonline.org/index.php

[34] Arif, H., Buchsbaum, R., Pierro, J., et al. (2010) Comparative Effectiveness of 10 Antiepileptic Drugs in Older Adults with Epilepsy. Archives of Neurology, 67, 408-415. https://doi.org/10.1001/archneurol.2010.49

[35] Bandstra, N., Camfield, C. and Camfield, P. (2008) Stigma of Epilepsy. Canadian Journal of Neurological Sciences, 35, 436-440. https://doi.org/10.1017/S0317167100009082

[36] Achor, J.U., Ezeala-Adikaibe, B.A., Obayi, O.N., Ezeruigbo, C.F.S., Ekenze, O.S. and Onodugo, O.D. (2017) The Stigma of Epilepsy among Outpatients in a Tertiary Hospital in Southeast Nigeria. Open Journal of Psychiatry, 7, 344-364. https://doi.org/10.4236/ojpsych.2017.74029

[37] American Psychiatric Association (2013) The Diagnostic and Statistical Manual of Mental Disorders, Fifth Edition (DSM-5). American Psychiatric Association, Virginia. https://doi.org/10.1176/appi.books.9780890425596

[38] Rössler, W. (2016) The Stigma of Mental Disorders: A Millennia-Long History of Social Exclusion and Prejudices. EMBO Reports, 17, 1250-1253.

https://doi.org/10.15252/embr.201643041 https://www.ncbi.nlm.nih.gov/pmc/articles/PMC5007563/

[39] Merriam-Webster Dictionary (n.d.) Suicide. https://www.merriam-webster.com/dictionary/suicide

[40] Harmer, B., Lee, S., Duong, T.V. and Saadabadi, A. (2022) Suicidal Ideation. StatPearls, Treasure Island. https://pubmed.ncbi.nlm.nih.gov/33351435/

[41] World Health Organization (2021) Fact Sheet: Suicide. https://www.who.int/news-room/fact-sheets/detail/suicide

[42] Chime, P.E., Chime, E.N. and Okechukwu, U.C. (2021) Mortality among Lassa Fever Patients: A Systematic Review. American Journal of Internal Medicine, 9, 87-90. https://doi.org/10.11648/j.ajim.20210902.15

[43] Deps, P. and Cruz, A. (2020) Why We Should Stop Using the Word Leprosy. The Lancet Infectious Diseases, 20, 900-901. https://doi.org/10.1016/S1473-3099(20)30723-4 